\title{
NECESSIDADES DE ORIENTAÇÃO PARA A ALTA DE PACIENTE COM PROBLEMA CIRÚRGICO GINECOLÓGICO
}

Raimunda Magalhães da Silva

SILVA, R. M. Necessidade de orientação para a alta de paciente com problema cirúrgico ginecológico. Rev. Esc. Enf. USP, São Paulo, 22 (n. especial): 68-82, ago. 1988.

O presente estudo visa fundamentar teoricamente a necessidade de orientação para a alta de paciente com problemas do aparelho ginecológico. Propõe plano de orientação, constando de dados necessários à aprendizagem, auto-cuidado, cuidado pós-alta e de critérios para avaliação de paciente internada.

O plano deverá ser desenvolvido pela equipe multiprofissional e durante o período de hospitalização. Fundamenta-se na importância que tem a orientação sobre saúde para paciente, assim como sua integração no plano terapêutico. Mostra a necessidade da atuação da enfermeira nessa área a fim de prevenir ou minimizar problemas e complicações futuras.

UNITERMOS: Alta do paciente. Enfermagem ginecológica. Planejamento da assistência ao paciente.

\section{1 - INTRODUÇÃO}

A elaboração deste estudo decorreu do fato de que as pacientes submetidas a cirurgia ginecológica geralmente apresentam uma série de necessidades, problemas e situações especiais que necessitam ser assis. tidas pela enfermeira.

A fim de atender essas necessidades é de vital importância a formulação e desenvolvimento de um plano de orientação sistematizada para a paciente e família, cujo enfoque deverá ser voltado para os aspectos globais observados durante a permanência hospitalar da paciente.

Segundo BURCHELL ${ }^{1}$, o aparelho genital feminino guarda uma relação pessoal e íntima com a vida emocional da mulher e dele decorrem problemas vitais como: menarca, sexualidade, planejamento familiar, gravidez, operações dos órgãos reprodutores e menopausa. As mudanças sociais, as atitudes mais livres, o sexo, o desejo de expressar sentimentos, resultam em perguntas as quais exigem da enfermeira orientação e compreensão humana sem olvidar os aspectos puramente científicos. Através da orientação, tem-se oportunidade de ajudar a paciente a melhorar a compreensão 
acerca do seu estado de saúde e sobre as decorrências implícitas em cirurgia ginecológica.

A enfermeira, como líder da totalidade da prática de enfermagem nas áreas de saúde comunitária ou hospitalar, deve desempenhar o papel de educadora ou orientadora, observando o inter-relacionamento enfermeirapaciente-família e/ou comunidade.

Segundo RAMOS ${ }^{13}$ "a orientação para a saúde consiste no conjunto de ensinamentos que visam à mudança de atitudes, de comportamento e o desenvolvimento da habilidade úteis à promoção, manutenção e à recuperação da saúde". Essa orientação é de importância fundamental para a paciente submetida a cirurgia ginecológica. Os complexos problemas, reais ou imaginários que podem influir na sua vida privada, poderão ser prevenidos ou minimizados, quando compreendidos pela paciente através da orientação educativa desenvolvida pela enfermeira durante a hospitalização.

As cirurgias ginecológicas constituem uma experiência traumática para a mulher, merecendo da equipe de enfermagem uma atenção especial e adequada. É preciso atentar-se para o fato de que, qualquer interferência nos órgãos de reprodução implica em impacto emocional. A resposta emocional está na ordem direta do significado do órgão de reprodução para cada pessoa, de seus aspectos culturais, situação de vida, personalidade e crença religiosa. Para SMITH ${ }^{18}$ os problemas ginecológicos têm grande repercussão na vida da mulher e provavelmente a enfermeira desconhece o impacto emocional específico que os originam. Daí ser a sua participação muito importante nos sentimentos e atitudes da paciente. A paciente deve contar com um ambiente adequado para que possa suportar suas emoções e a enfermeira deve usar de uma estratégia de orientação tal que, nas suas mínimas expressões, seja entendido o seu grau de ansiedade.

$O$ atendimento das necessidades de aprendizagem da paciente é uma responsabilidade fundamental da enfermeira. $O$ aprendizado do indivíduo se processa através de várias maneiras: informação, orientação, leitura, demonstração, etc., e isto possibilita desenvolver habilidades e aplicar os conhecimentos adquiridos na adaptação às novas situações. Uma das queixas mais freqüentes da paciente é a insuficiência de informações rece. bidas. Além disso, há evidência de que as informações e ensino condizentes com as necessidades da paciente contribuem para a recuperação e reabi. litação da pessoa doente. A enfermeira deve sempre ter em mente a reabilitação da paciente quando planeja um programa de ensino para a mesma e deve lembrar que as necessidades variam de paciente para paciente, portanto o plano de ensino deve ser individualizado. A necessidade de aprendizagem depende de vários fatores, tais como: experiência de hospitalização, problemas anteriores de saúde, experiência pregressa com relação a sua condição atual, a idade, o sexo, estado civil, educação e a situação econômica da paciente.

O trabalho visa fundamentar teoricamente a atuação do profissional de enfermagem frente a necessidade de aprendizagem da paciente com 
indicação de cirurgia ginecológica e propor um plano de orientação constando informações necessárias para paciente e famílíia que deverá ser desenvolvido pela equipe multiprofissional durante a hospitalização.

\section{II - A ENFERMEIRA FACE AOS TRAUMAS DE CIRURGIAS GINECOLOGICAS}

São inúmeros e diversificados os traumas decorrentes das cirurgias ginecológicas, podendo os mesmos serem agrupados em físicos, mentais, sociais e espirituais. Esses traumas, temporários ou permanentes, exercem influências muitas vezes desastrosas para o indivíduo, podendo refletir sobremaneira na família e comunidade. São eles caracterizados, na maioria das ocorrências, por mutilações, diminuição da funcionalidade do órgão e incapacidade de reprodução.

Face a tal problemática, a paciente apresenta uma série de necessidades que precisam ser compreendidas, assistidas e superadas, tais como: aceitar as limitações impostas pela doença; aprender a agir dentro dessas limitações; ser aceita como membro da família e da comunidade; aprender habilidades específicas e obter esclarecimentos sobre a maneira de viver com a saúde limitada. A enfermeira desempenha um papel importantíssimo junto à paciente e família no atendimento às necessidades identificadas.

ULFELDER ${ }^{21}$ ressalta a premência de se lutar, em todos os casos, por uma recuperação suave e sem complicações. Registra que tanto a paciente como seu esposo devem tomar conhecimento da natureza da cirurgia indicada e discutir a possibilidade de seus efeitos na fertilidade, nas relações sexuais e na menopausa. Pesam ainda, os temores e ansiedades que a paciente experimenta, temores esses quando há eventualidade de câncer, perda da capacidade reprodutora, da feminilidade e alteração da imagem corporal.

A incapacidade reprodutora na mulher, pós-cirurgia ginecológica, propicia o aparecimento de sérios problemas irreversíveis, principalmente quando a mulher nunca teve filhos. Quando esses problemas não são prevenidos ou diminuídos, tendem a se agravar e assim desencadear outras complicações mais sérias. A tendência à complicação de ordem emocional e social, assume maior vulto, em caso de cirurgia radical devido ao câncer, por implicar na interrupção das relações sexuais, afetando diretamente as relações conjugais. Outra situação que traz sérias conseqüências é a indicação de cirurgia para esclarecimento de diagnóstico em adolescentes. Neste período estão se formando atitudes a respeito de mudanças corporais, acarretando transtornos que podem perdurar por toda a vida.

As reações apresentam-se de várias maneiras, tais como: tendência a auto-controle, limitações das percepções e sentimentos, aceitação com estoicismo do inevitável ou demonstração de uma aparência de satisfação. Essas mudanças são perfeitamente notáveis e, com uma pequena ajuda, a paciente protege-se contra o medo, o sofrimento, e exerce um papel mais passivo e operativo. 
A paciente a ser operada preocupa-se com o procedimento cirúrgico; tem medo da dor, da anestesia, de ficar incapacitada, de mostrar que está com medo e sobretudo medo de morrer. Numa tentativa da paciente controlar este medo, pode inibir a função mental e chegar a um estado letárgico ou apático que perdura de quatro a cinco dias. A paciente sofre sentimentos de perda, até mesmo perda da integridade física, e a enfermeira talvez não tenha consciência do efeito destes sentimentos na recuperação imediata ou na adaptação eventual à perda.

Algumas pacientes superam as reações de perda sozinhas, outras precisam de ajuda e, sem esta, não são capazes de obter bons resultados pós-cirurgia. Muitas vezes essa ajuda é muito pequena e simples, basta que a enfermeira entenda o que está se passando com a paciente e lhe dedique algum tempo para que ela possa conversar e falar sobre seus sentimentos. ORLANDO ${ }^{9}$ enfatiza que a enfermeira deve responsabilizar-se pela análise de reações estranhas positivas ou negativas, que interfiram na ajuda às pacientes.

\section{III - A EDUCAÇÃO COMO ATIVIDADE PRIMARIA DA ENFERMEIRA}

A educação para a saúde constitui uma das medidas mais eficazes, no preparo da paciente a tratamento cirúrgico, nos possíveis problemas emocionais e traumáticos e na reeducação, principalmente quando não se consegue impedir as limitações ou incapacidades advindas do problema cirúrgico.

HENDERSON ${ }^{5}$ num consenso quanto a eficácia do trabalho educativo, menciona que "a recuperação e o controle da doença dependem dessa reeducação, cuja ação impõe tributos pesados à capacidade profissional dos especialistas, quando os melhores esquemas de tratamento não atingirem seu objetivo de prevenir ou impedir que a paciente se torne incapacitada".

A atividade educativa pode ser desenvolvida em todas as ocasiões, especialmente na comunidade e na prestação de assistência. Deve ser centrada no auto-cuidado, na participação ativa da paciente na terpêutica, no potencial de auto-confiança de cada paciente, em suas individualidades e essencialmente no preparo para a alta. Assim, a orientação sistematizada, por ser uma das estratégias que permite à paciente uma melhor adaptação à vida, deve ser enfatizada. O trabalho educativo é inerente a todos os elementos da equipe de saúde, figurando como uma das respon. sabilidades primárias a serem assumidas pela enfermeira. SILVA ${ }^{15}$ descreve a educação como um processo básico para o trabalho de saúde, cabendo à enfermeira despertar o indivíduo e família para melhor obtenção dos meios de prevenção da doença, promoção e recuperação da saúde o mais rápido possível. A enfermagem é a mola propulsora das ações educativas devido a multiplicidade de tarefas que desenvolve junto à paciente e família, por permanecer maior parte de tempo junto ao doente e pela possibilidade de propiciar melhor integração da mesma à família e comunidade. 
A hospitalização favorece um trabalho educativo compatível com a realidade desse binômio, uma vez que, nessa ocasião, obtêm-se informações quanto aos estilos de vida no lar da paciente e família, possibilitando, desta forma, uma educação mais segura, precisa e compatível com suas necessidades bio-psico-sócio-espirituais e recursos existentes.

Quanto aos aspectos psicológicos e espiritual, segundo PAIM ${ }^{10}$, o ho. mem não vive apenas no presente, pois seu tempo depende da importância do acontecimento, do significado da experiência, de suas esperanças, ansiedades e progresso como pessoa. A enfermeira deve preocupar-se em "buscar uma atitude coerente com a responsabilidade que deve ser assumida frente às mais diversas manifestações da paciente, e que possa equi. valer, em qualquer situação, à conduta profissional exigida e sistematicamente orientada para a identificação e o atendimento das necessidades subjacentes aos mais diferenciados tipos de reações individuais, neces. sidades que são singulares a cada pessoa em determinada situação".

\section{IV - ORIENTAÇÃO CENTRADA NA ALTA DA PACIENTE SUBMETIDA A CIRURGIA GINECOLOGICA}

O desempenho da enfermeira na orientação à paciente e família para a alta é um importante fator na utilização dos recursos que devem ser aplicados. $O$ bom desempenho permite mudanças de comportamento a curto ou a longo prazo e possibilita à paciente expressar suas preocupações, sentimentos e dúvidas quanto aos problemas relativos à saúde.

RIBEIRO ${ }^{14}$ reitera a importância do papel da enfermeira na orientação e preparação de paciente, para assumirem responsabilidades no plano terapêutico e aproveitarem adequadamente os recursos da comunidade e insti. tuição, de forma que suas necessidades sejam atendidas.

0 preparo qualitativo para a alta reflete-se num melhor seguimento de caso e maior integração da paciente à família e comunidade. Como afirma Du GAS ${ }^{3}$ e WINSLOW ${ }^{22}$, que esta ação deve ser iniciada na admissão, seguindo-se a hospitalização, a convalescença, até o retorno às atividades normais. $O$ consenso evidenciado pelos autores caracteriza a extensão da responsabilidade da enfermeira no preparo para a alta, pois implica na interação da paciente e família, bem como na sua assistência e reintegração dentro do contexto da instituição familiar e comunidade.

Para SOUZA ${ }^{19}$ e McCLAIN ${ }^{7}$, a alta significa a transferência da responsabilidade da continuação do tratamento para a paciente, família, médico particular ou para outra instituição.

Du GAS ${ }^{3}$ chama a atenção para as sensações sofridas pela paciente ao receber a alta, por exemplo, de alegria por reunir-se à família e, muitas vezes, paradoxalmente, um sentimento de medo e ansiedade em relação ao futuro, temores quanto à responsabilidade que vai assumir e dúvidas em relação a sua capacidade de atuação como membro da família e comunidade. 
SOUZA ${ }^{19}$ ressalta que o preparo para a alta é um processo que envolve cooperação e inter-relação entre enfermeira-paciente-família. É uma ação que deve ser planejada e executada pela equipe multiprofissional (médico, enfermeira, assistente social e nutricionista), família ou qualquer outra pessoa interessada pela paciente. Essa ação desenvolvida pela equipe multiprofissional é relatada por $52 \%$ das pacientes com problemas cirúrgico ginecológico. SILVA ${ }^{16}$.

As expectativas da paciente quanto à orientação para a alta, têm sido expressas em publicações diversas e pesquisas realizadas.

FUERST ${ }^{4}$ registra que, em geral, a paciente espera que a enfermeira a oriente quanto aos cuidados relativos à saúde. A paciente considera a cirurgia uma experiência assustadora. Teme o desconhecimento e tem receios de ser abandonada sem orientação e sem atendimento às suas dúvidas que poderiam ser externadas através de perguntas.

POHL ${ }^{12}$ põe em relevo o papel da enfermeira na orientação. Opina que a mesma contribui para a a promoção da saúde do indiví́duo por estar freqüentemente em contato com as pessoas e família.

Demonstra o valor da educação ao expressar que a pessoa assume responsabilidades consigo mesmo e com os outros elementos da família e comunidade. Afirma que as pessoas são capazes de aprender a importância da saúde, como adquiríla e mantê-la em muitos aspectos de vida.

COSPER $^{2}$ enfatiza que o ensino para a alta é considerado parte do cuidado da paciente hospitalizada e para que ela tenha conhecimento dos problemas é necessário que seja prévia e adequadamente preparada para a alta. Em sua pesquisa com 40 pacientes histerectomizadas, constatou que 16 declararam durante as entrevistas que necessitavam de mais informações na primeira semana pós-alta.

O plano minucioso para a alta, de acordo com WINSLOW ${ }^{22}$ é muito importante para a paciente operada. As instruções contidas nesse plano devem ser fornecidas à paciente e família, com antecedência, a fim de permitir que leiam, interpretem e esclareçam as dúvidas que porventura surgirem, servindo ainda como referências posteriores.

$\mathrm{Na}$ orientação para a alta os seguintes tópicos devem, sobremaneira, ser enfatizados: promoção e recuperação da saúde; cuidados indispensá. veis após a alta; medidas de proteção quanto a novas experiências e efeitos adversos; reintegração na célula familiar e comunidade; importância da participação dinâmica nas atividades que exercia anteriormente; e adaptação ou limitações a serem assumidas.

As estratégias a serem empregadas na orientação podem ser agrupadas em:

a) Apoio - que consiste em encorajar a paciente a participar das atividades permitidas;

b) Aconselhamento - implica em oferecer à paciente um programa de ação direta e total. Trata-se de uma atividade em que o aconselhador exerce 
certo papel dominante, embora sejam permitidos a troca recíproca de informações e o diálogo;

c) Gratificação das Necessidades - é um meio auxiliar da terapia, envolvendo um clima de receptividacie entre orientador-paciente e família. É empregado com maior freqüência nas situações traumáticas e de tensões. Usada geralmente em grupo de pacientes de baixo nível sócio-econômico e cultural;

d) Explicação verbal no leito - envolve uma modalidade de palestras e entrevista estilizadas, empregada quando se visa a prestar e obter informações ou cooperação mútua. Possibilita à paciente falar e fazer perguntas;

e) Grupos de Discussão - é uma modalidade de educação sócioindividualizada que visa a atender as diferenças individuais e o processo de trabalho em grupo com o objetivo de permitir melhor socialização e trabalho em equipe;

f) Palestra - é a exposição verbal de aspectos relativos à saúde, usada principalmente quando a paciente apresentar evidências de pouca maturidade ou falta de domínio no assunto; poderá, outrossim, atender as expectativas de grupos;

g) Demonstração - é um valioso complemento aducativo utilizado quando se procura orientar a execução de uma atividade que exija uma repetição pela paciente do que foi demonstrado, levando-a a habilidade e automatismo;

h) Instruções Escritas - compõem-se de uma guia por escrito com informações minuciosas em relação à assistência, extensivas à família. Devem ser aplicadas como um reforço ao sistema de orientação oferecido. $\mathrm{O}$ conteúdo informativo deve ser dividido de preferência em unidades e apresentado sob a forma de técnica de intervalo.

Algumas dessas estratégias, são preconizadas por SMALL ${ }^{17} \mathrm{e}$ WINSLOW ${ }^{22}$, sendo que o primeiro ressalta o aconselhamento e gratificação das necessidades. Já WINSLOW ${ }^{22}$ salienta a instrução escrita, explicação oral, demonstração e grupo de discussão. Enquanto que ORLANDO ${ }^{9}$ valoriza a instrução, sugestão, orientação, explicação, informação, solicitação e pergunta.

A orientação para a alta deve estar fundamentada:

a) $\mathrm{Na}$ identificação prévia da personalidade da paciente e dos problemas que a afetam.

BURCHELL ${ }^{1}$ acentua a necessidade de identificar previamente os problemas da paciente e do conhecimento da sua personalidade, para que se possa compreender a magnitude desses problemas antes de qualquer decisão terapêutica. viduais.

b) No atendimento das necessidades básicas e características indi-

PEPLAU ${ }^{11}$ declara que a orientação deve abranger aspectos tais como: fazer com que a paciente viva de forma satisfatória, satisfaça suas necessidades particulares e exerça suas próprias habilidades. 
c) Na mobilização de meios para reeducação da paciente e família.

HORTA $^{6}$ especifica alguns aspectos que evidenciam a reeducação: integração social, capacidade de resolver problemas e mudanças quanto à utilização de hábitos, medidas de promoção e recuperação da saúde.

d) $\mathrm{Na}$ interação enfermeira-paciente.

NAKAMAE ${ }^{8}$ retrata que a interação enfermeira-paciente, quando efetiva, contribui para a aprendizagem, aquisição e modificação do comportamento da paciente. Ressalta que uma ação mútua e dinâmica entre enfermeira-paciente estimula a busca de orientação emocional e física.

Para TRAVELBEE ${ }^{20}$ a interação enfermeira- paciente ocorre durante um periodo particular da vida de ambos, portanto, não pode ser repetida ou imitada. Uma característica desta interação é que cada encontro é único e original. Antes da interação, a enfermeira precisa organizar suas idéias e pensamentos, como também conceitualizar o que quer alcançar durante a mesma.

e) Adequação da orientação.

NAKAMAE ${ }^{8}$ descreve que a orientação deve estar à altura da compreensão da paciente e baseada na verdade. É necessário conduzí-la de tal forma que assuma a realidade com segurança e apoio.

PEPLAU ${ }^{11}$ pormenoriza que a orientação, quando exercida individualmente ou em grupo, possibilita ao profissional a interpretação das respostas da paciente e a intervenção adequada para modificar as idéias e condutas.

A orientação centrada no preparo para a alta oferece inúmeras vantagens; dentre elas, destacam-se:

- Permissão para que a enfermeira examine a importância terapêutica da interação e eficácia da comunicação verbal entre profissionalpaciente;

- Possibilidade e oportunidade de a paciente se comunicar e compartilhar problemas;

- Oportunidade de mudança de comportamento ligada à saúde;

- Favorecimento do atendimento global das necessidades assis. tenciais; nâmica.

- Contribuição para uma assistência científica, progressiva e di-

Descreve, ainda, as características necessárias a uma enfermeira para desenvolver a orientação para a alta:

- Servir de exemplo à paciente;

- Manter boa atitude profissional;

- Respeitar a paciente;

- Avaliar o grau de desenvolvimento intelectual da paciente; 
racional;

- Orientar a paciente para interpretar suas experiências, de forma

- Fazer perguntas sensatas para facilitar a discussão;

- Estudar e aplicar conceitos teóricos na orientação.

TRAVELBEE ${ }^{20}$ recomenda que a enfermeira ajude a paciente a discutir francamente seus pensamentos e sentimentos em relação à alta, identificar o que teme e dizer os problemas específicos que originam os sentimentos de angústia, incapacidade ou incompetência.

SILVA ,R. M. The need of discharge orientation to patients with gynecological problems. Rev. Esc. Ent. USP, São Paulo, 22 (special issue): 68-82, Aug. 1988.

The present study has in view to base the necessary theoretical of orientation to discharge a patient with troubles in gynecological system, to propose a plan of orientation, that consist in data that is necessary to apprenticeship, self-care, carefulness Post-Discharge and discernment to evaluation of the patient that is hospitalized. The plan shall be development for a multi-practitioner team and during the time of hospitalization. In bases itself in the importance that the orientation systematized has about health for the patient, as well its integration in the therapeutic plan. The plan shows the necessity of performance of the nurse in this field in order to avoid or to minimize troubles, and complications in the future.

UNITERMS: Patient discharge. Gynecologic nursing. Patient care planning.

\section{REFERENCIAS BIBLIOGRAFICAS}

1. BURCHELL, R. C. Orientación ginecológica en el consultório. Clin. Obstét. Ginecol. México, 1:175-6, mar. 1978.

2. COSPER, B. et alii. Characteristics of posthospitalization recovery following hysterectomy. JOGN Nursing. Philadelphia, 7(3):7-11, May/June 1978.

3. Du GLAS, B. W. Enfermagem prática. 4. ed. Rio de Janeiro, Interamericana, 1984. cap. 6, 9, 10, 15.

4. FUERST, E. V. et alii. Fundamentos de enfermagem. 5. ed. Rio de Janeiro, Inter. americana, 1977. p. 110.

5. HENDERSON, V. Principios básicos do cuidado de enfermagem. Rio de Janeiro, Associação Brasileira de Enfermagem, 1962. p. 12, 57, 60.

6. HORTA, W. A. Assistência de enfermagem ao adulto idoso. Enf. Novas Dimens., São Paulo, 4(5):268-73, set./out. 1978.

7. McClAIN, M. E. \& GRAGG, S. H. Principios científicos da enfermagem. 2. ed. Rio de Janeiro, Científica, 1970.

8. NAKAMAE, D. D. Preparo do paciente para a alta hospitalar: descrição de uma situação. Rev. Bras. Enf., Brasília, 29(2):36-9, abr./jun. 1976.

9. ORLANDO, I. J. O relacionamento dinâmico enfermeira-paciente. São Paulo, EPU, 1978. p. $70-3$. 
10. PAIM, L. Algumas considerações de enfermagem sobre as necessidades psico-sociais e psico-espirtuais dos pacientes. Rev. Bras. Enf., Brasília, 32(2):160-66, abr./jun. 1979.

11. PEPLAU, H. E. Principios básicos para la orientación del paciente. Washington, Organización Panamericana del Salud, 1968.

12. POHL, M. L. The teaching function on the nursing practitioner. 3. ed. Dubuque, Brown, 1978.

13. RAMOS, S. M. Necessidades de orientação à saúde do paciente diabético. Rev. Bras. Enf., Brasília, 29(4):38-41, out./dez. 1976.

14. RIBEIRO, C. M. Atividades de enfermagem. Rev. Esc. Enf. USP, São Paulo,3(1):5-8, mar. 1969.

15. SILVA, M. J. N. D. O ensino da assistência educativa de enfermagem. Rev. Bras. Enf., Rio de Janeiro, 15(1/2:14-38, jan./abr. 1972.

16. SILVA, R. M. Orientação para a alta de paciente submetido a cirurgia ginecológica - um estudo exploratório. Rio de Janeiro, 1980. (Dissertação de mestrado Universidade Federal do Rio de Janeiro).

17. SMALL, L. As psicoterapias breves. Rio de Janeiro, Imago, 1974 . p. 84-117.

18. SMITH, D. W. et alii. Enfermeria medicoquirurgica. 3. ed. México, Interamericana, 1971. p. 876.

19. SOUZA, E. F. Novo manual de enfermagem. Rio de Janeiro, Cultura Médica, 1976. p. 46-51.

20. TRAVELBE, J. Intervención en enfermeria psiquiatrica. Carvajal, Organização Panamericana de la Salud, 1979 . p. 125-59.

21. ULFELDER, M. Cirurgia ginecológica. In: RANDAL, H. T. Manual dos cuidados pré e pós-operatórios. Rio de Janeiro, Guanabara Koogan, 1969. p. 409-14.

22. WINSLOW, E. H. et alii. Operative technique and paptient education. Nurs. Clin. North Amer., 11(2):379-89, June 1976. 


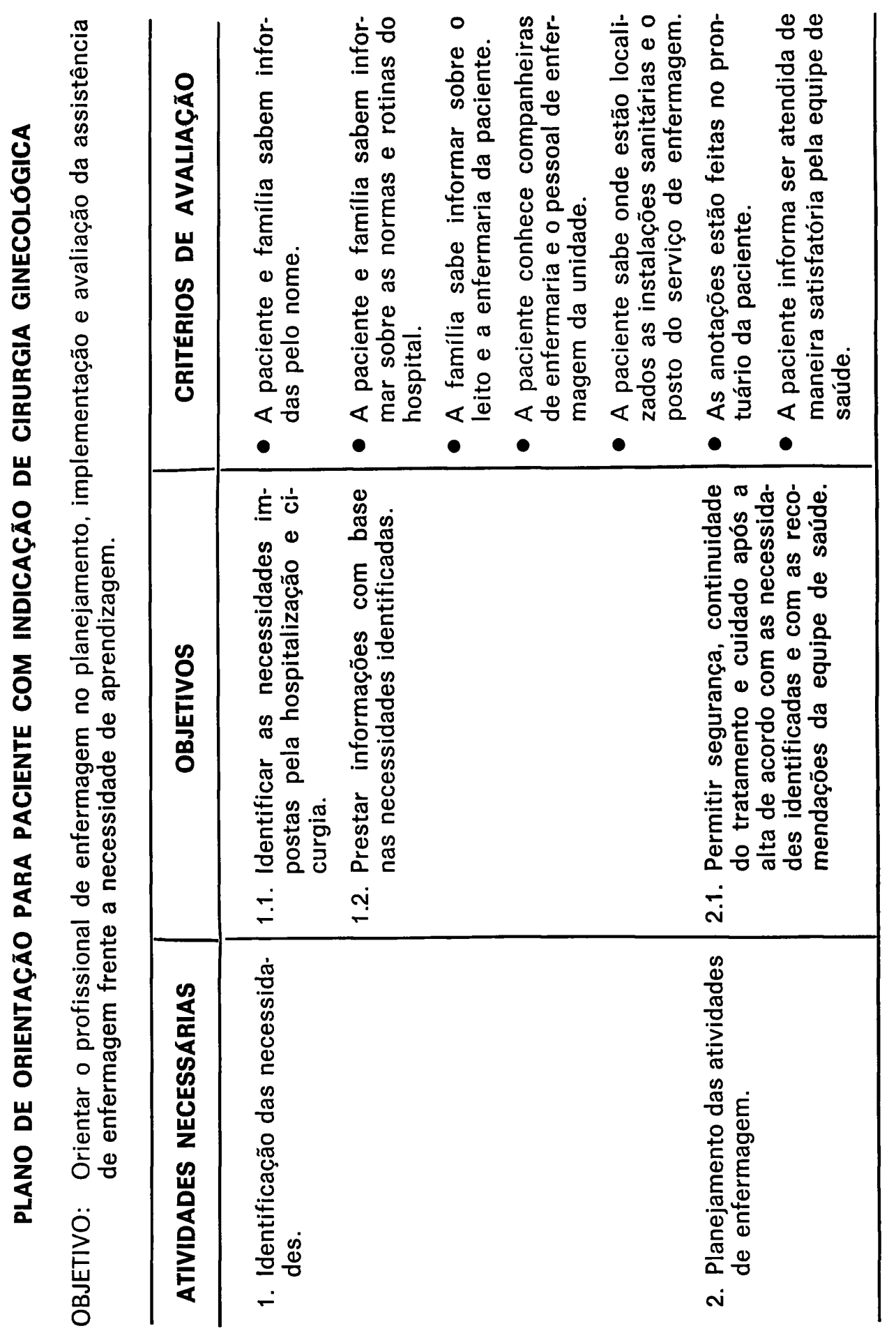




\begin{tabular}{|c|c|c|c|c|c|c|c|c|}
\hline 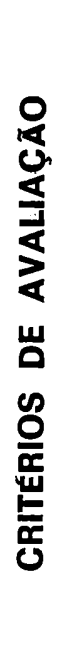 & 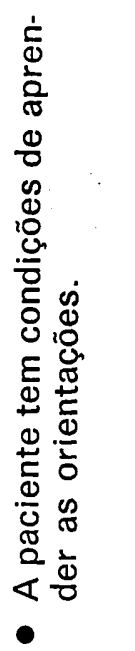 & 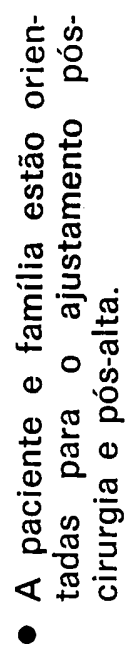 & 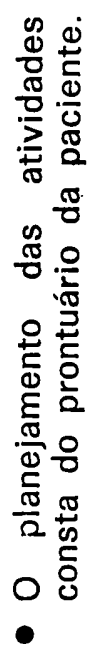 & 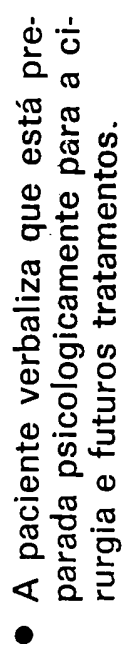 & ? & 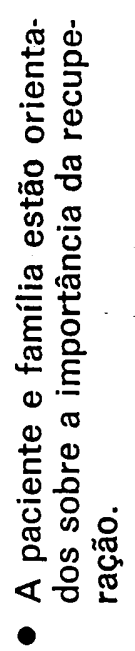 & 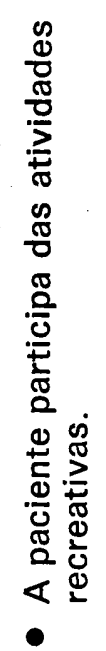 & 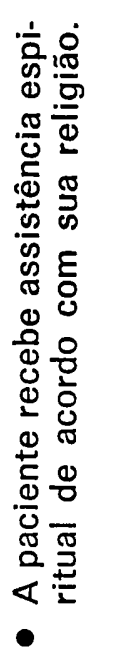 \\
\hline 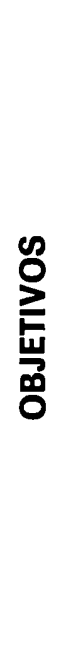 & 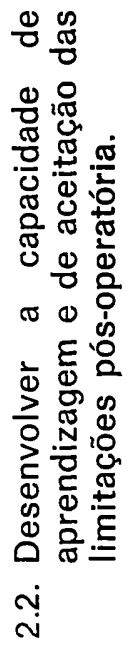 & 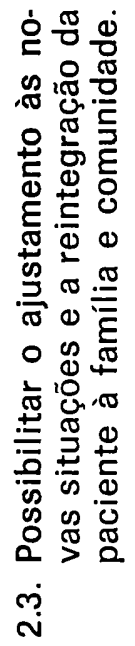 & & 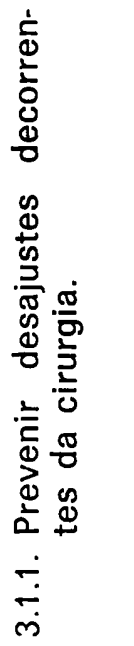 & 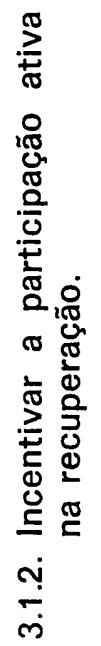 & 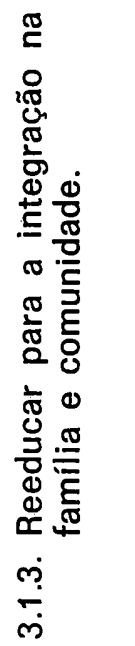 & 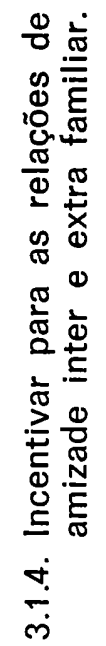 & 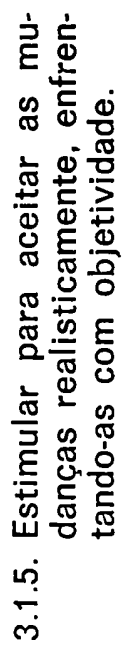 \\
\hline 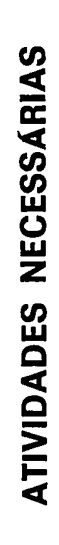 & & & & 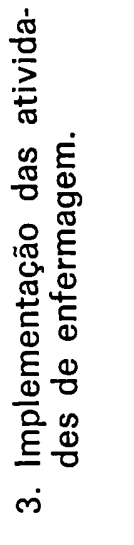 & 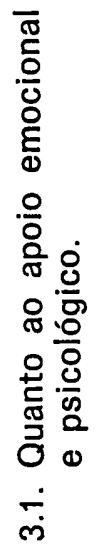 & & & \\
\hline
\end{tabular}




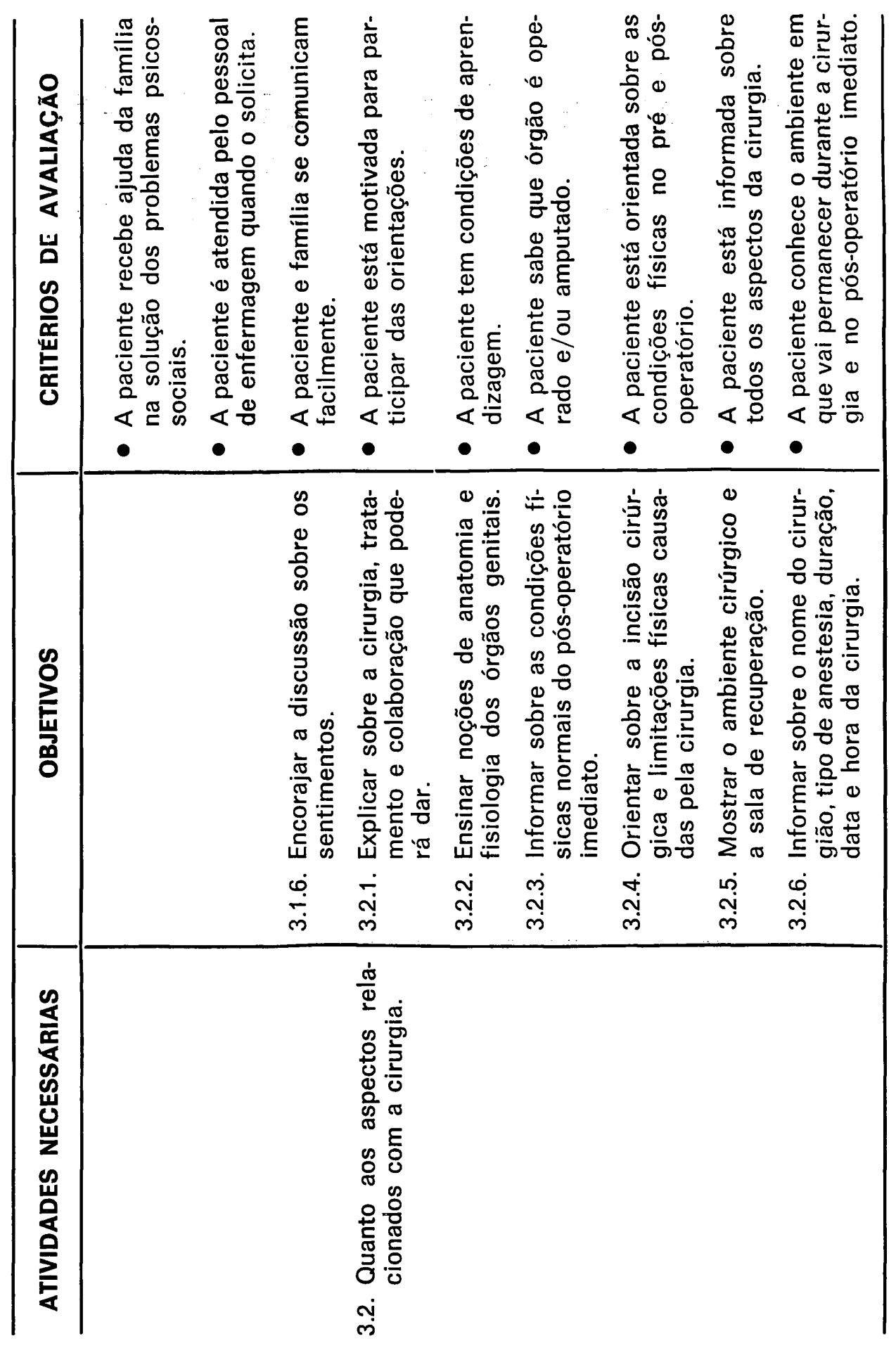




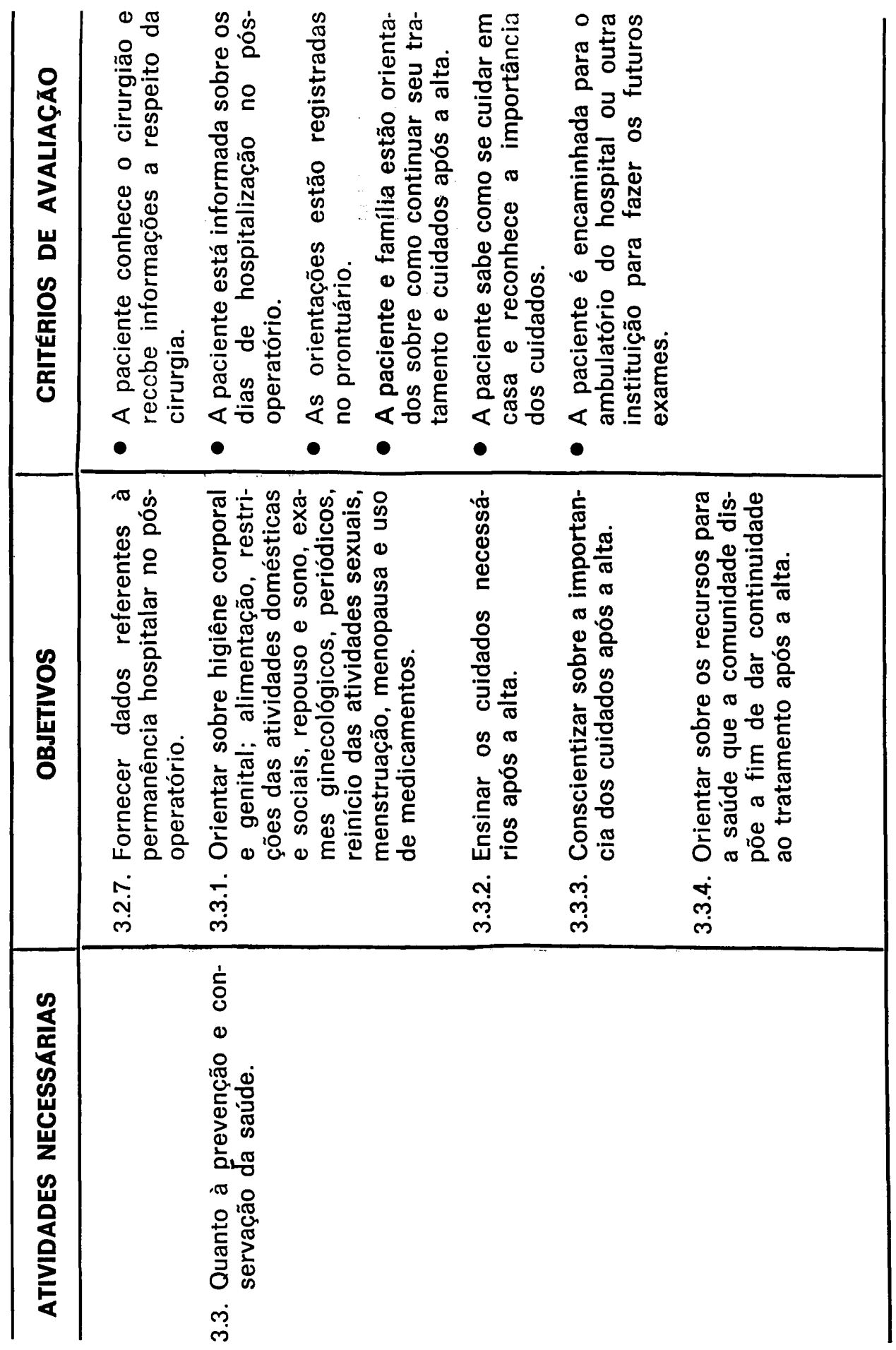

Rev. Esc. Enf. USP, São Paulo, 22 (n. especial): 68-82, lun. 1988. 


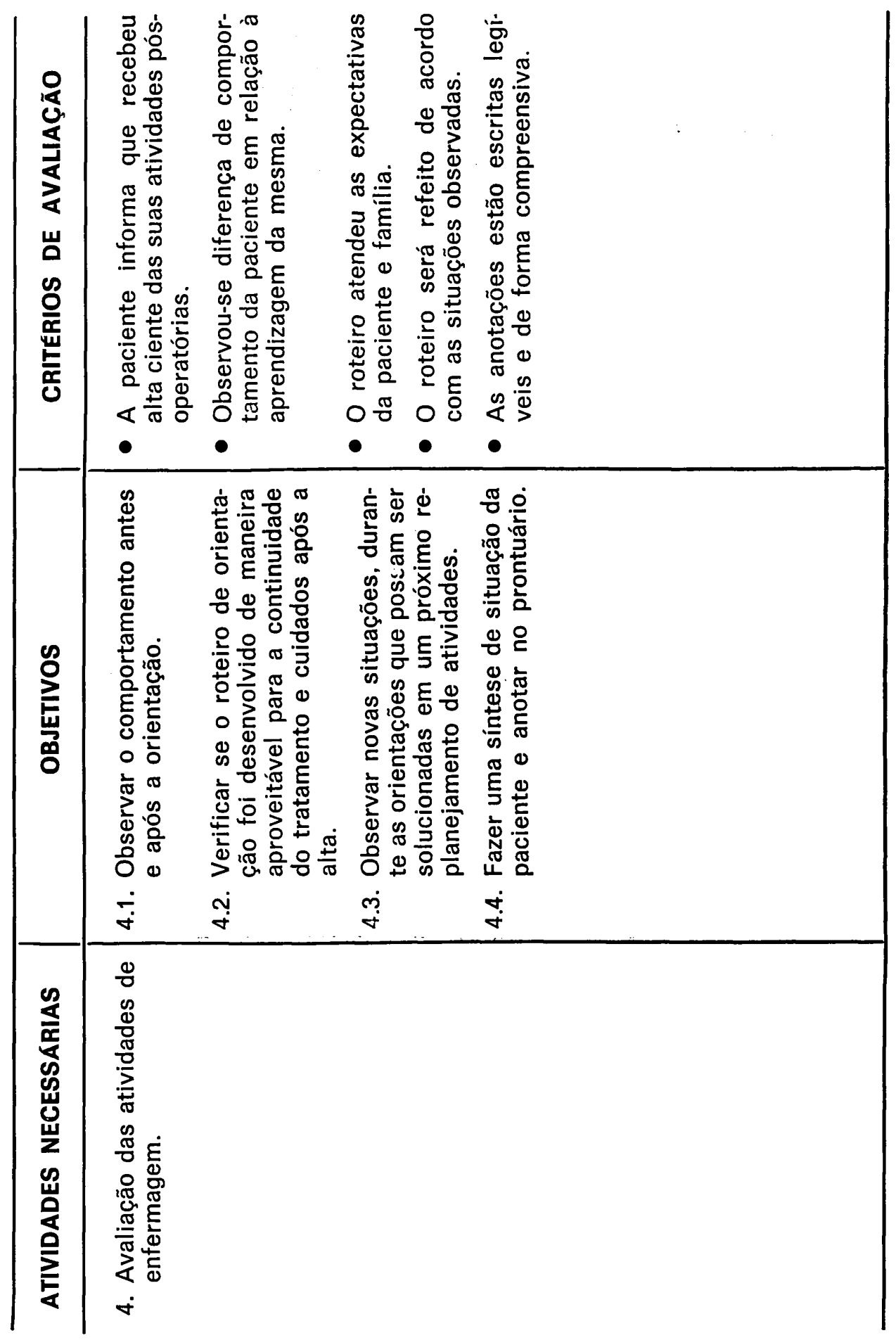

